\title{
Assessment of Serum Selenium and Zinc in Esophageal Cancer Patients
}

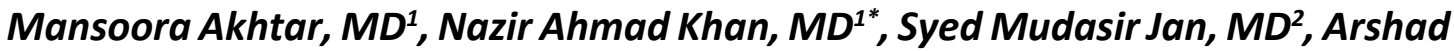 Manzoor, MD', Nazir Ahmad Dar, MSc', M Maqbool Lone, MD ${ }^{1}$}

${ }^{1}$ Department of Radiation Oncology, SKIMS, Srinagar, Jammu \& Kashmir, India

${ }^{2}$ Department of Clinical Biochemistry, SKIMS, Srinagar, Jammu \& Kashmir, India

*Corresponding author: Nazir Ahmad khan, Professor, Department of Radiation Oncology, Sher-i-Kashmir Institute of Medical Sciences (SKIMS), Srinagar, Jammu \& Kashmir, India, Tel: 9419080770

\begin{abstract}
Background: Oesophageal cancer represents a major health problem, continues to have very poor prognosis despite advances in its management that include improved surgical technique, neoadjuvant and adjuvant therapy as there seems to be little project for early detection and treatment, a better understanding of the risk factors may suggest opportunity for its primary prevention.
\end{abstract}

Aims and objective: To determine the role of trace elements, like selenium and zinc as a risk factor in carcinoma oesophagus.

Materials and methods: A total of 200 cases of histology confirmed carcinoma oesophagus (study group) and 200 case of healthy individual (control group) were enrolled in this study prospectively ,besides baseline investigations and imaging modalities required for staging, analysis of trace elements, selenium and zinc was done in all cases prior treatment.

Results: Majority (58\%) the cases in both groups were in the age groups of $51-70$ years, males were predominant $58.5 \%$ and $65.5 \%$ in the study and control group respectively. Mean plasma zinc level was significantly lower in the study group 8.37 than control group 12.12 , similarly selenium level was 10.76 in the study group compared to 27.18 in the control group which was statistically significant $p$-value ( $p$-value $<0.011)$.

Conclusion: Substantial deficiency of selenium and zinc observed in the study group, however further studies are required to establish the deficiency of these trace elements as risk factor in carcinoma oesophagus.

\section{Keywords}

Esophagus, Selenium, Zinc, Risk factors

\section{Introduction}

The esophageal cancer (EC) is eighth most common cancer and sixth most common cause of cancer related death in the world [1]. Carcinoma esophagus is common in some areas of world viz. Iran, India, China, Ireland, Japan, UK and region around Caspian sea [2]. In India, esophageal carcinoma is the most common malignancy involving gastrointestinal tract in Karnataka, Kerela, Tamil Nadu and Assam. In Kashmir it is ranking number one, but there is scarcity of epidemiological studies in this regard [3]. Esophageal cancer is considered a serious malignancy with respect to prognosis as it has fatal outcome in majority of cases $[4,5]$. Esophageal cancer still has a 5 year survival of $<20 \%$ in the united states [1]. There are some known risk factors like tobacco and alcohol consumption which increases the chances of developing cancer esophagus however further research to identify risk factors in this fatal cancer will keep this cancer under check.

Selenium has been studied in relation to cancer risk, and most epidemiologic studies have been performed on breast, colorectal, lung, gastric, bladder, and prostate cancer [6]. Evidence from observational studies so far suggests that selenium is inversely associated with prostate cancer and possibly with lung and gastric cancer [6]. The reason for the interest in selenium in relation to cancer aetiology is the antioxidant capacity of the selenium-dependent glutathione peroxides enzymes $[7,8]$. Other possible mechanisms through which

Citation: Akhtar M, Khan NA, Jan SM, Manzoor A, Dar NA, et al. (2020) Assessment of Serum Selenium and Zinc in Esophageal Cancer Patients. Int J Cancer Clin Res 7:138. doi.org/10.23937/23783419/1410139

Accepted: June 27, 2020; Published: June 29, 2020

Copyright: (c) 2020 Akhtar M, et al. This is an open-access article distributed under the terms of the Creative Commons Attribution License, which permits unrestricted use, distribution, and reproduction in any medium, provided the original author and source are credited. 
selenium could be associated with lower cancer risk include reduction of inflammation, induction of detoxifying phase II enzymes, increase of p53, alteration of DNA methylation, blockage of the cell cycle, induction of apoptosis of cancer cells, and inhibition of angiogenesis [8]. Studies have reported lower levels of zinc in the serum of newly diagnosed oesophageal carcinoma patients than normal controls [9]. In this regard we conducted this study to find out the role of trace elements like selenium and zinc in carcinoma oesophagus in our set of patients.

\section{Materials and Methods}

Patients with histological confirmed carcinoma esophagus who were registered at our regional cancer center between June 2016 to June 2018 were enrolled in the study. All the patients were investigated and staged thoroughly. Besides complete blood count, Biochemistry, Imaging modalities, analysis of trace elements, like Zinc, and Selenium, were determined in all patients prior to treatment. This was a prospective study in which patients characteristics with regard to gender, age, presentation, locality, investigations and treatment prescribed in each case were studied in detail. History was thoroughly taken to rule out any co-morbid conditions for which patient was on minerals, vitamins or any other combination of drugs, during last six months were not included in the study.

A 5-ml venous blood sample was collected from the antecubital vein of each of the esophageal cancer patients and healthy volunteers, in between 8 to 10 a.m., after an overnight fasting. The venous blood samples were collected in plain screw cap specimen tube and then left for 30 minutes for retraction, after which centrifugation was carried out at $3000 \mathrm{~g}$ for 5 minutes and the supernatant serum was aspirated using Pasteur pipette into another plain tube. The collected supernatant was then pooled and stored at $-20^{\circ} \mathrm{C}$ until the time of analysis. At the time of analysis $2 \mathrm{ml}$ of thawed supernatant serum sample after thorough mixing were added to a clean $10 \mathrm{ml}$ centrifuge tube and diluted to $10 \mathrm{ml}$ with hydrochloric acid. The diluted serum sample was then centrifuged for $3 \mathrm{~min}$ as 3000 revolution per min to remove cellular debris before it was aspirated for analysis of zinc by atomic absorption spectrophotometrically, while as selenium was analyzed by atomic absorption.

\section{Statistical analysis}

Statistical analysis was done by using SPSS V20 Continuous variables were expressed as Mean \pm SD and categorical variables were summarized as frequencies and percentages. Student's independent t-test was employed for comparing continuous variables. Chi-square test was applied for comparing categorical variables. All values was discussed at $5 \%$ level of significance (i.e $p<$ 0.05 ) was treated as significant.

\section{Results}

Out of 400 cases enrolled in this study 200 were cases of carcinoma oesophagus (study group) and 200 were healthy controls (control group) from same family and same socio-economic status. The mean age of patients with esophageal cancer was $62.1 \pm 12.61$ years, males were predominant $58.5 \%$ than females $41.5 \%$ which was not statistically significant ( $p$-value $<0.05$ ). Dysphasia was most common presentation in $92 \%$ of cases, $37.5 \%$ of patients had lesion in mid thoracic region followed by upper thoracic region in $24.5 \%$ as shown in Table 1.

We observed that the mean selenium in cancer oesophagus was less (i.e $54.2 \pm 10.76$ ) as compared to control group (105 \pm 27.18 ) but statistically we found that there was significant relationship between cases and control group (i.e. $p<0.05)$ as same as mean zinc $(56.8$ \pm 8.37 ) was less in cases as compared to control (88.3 \pm 12.12) and statistically there was significant relation (i.e.

Table 1: Age and gender wise distribution of cases and controls.

\begin{tabular}{|c|c|c|c|c|c|}
\hline \multirow{2}{*}{ Age (years) } & \multicolumn{2}{|c|}{ Study } & \multicolumn{2}{|c|}{ Controls } & \multirow{2}{*}{ P-value } \\
\hline & $\mathbf{N}$ & $\%$ & $\mathbf{N}$ & $\%$ & \\
\hline$<30$ & 3 & 1.5 & 9 & 4.5 & \multirow{8}{*}{0.096} \\
\hline $31-40$ & 8 & 4.0 & 15 & 7.5 & \\
\hline $41-50$ & 31 & 15.5 & 34 & 17.0 & \\
\hline $51-60$ & 57 & 28.5 & 65 & 32.5 & \\
\hline $61-70$ & 59 & 29.5 & 54 & 27.0 & \\
\hline$>70$ & 42 & 21.0 & 23 & 11.5 & \\
\hline Total & 200 & 100 & 200 & 100 & \\
\hline Mean \pm SD & \multicolumn{2}{|c|}{$62.1 \pm 12.61$} & \multicolumn{2}{|c|}{$59.8 \pm 14.87$} & \\
\hline \multirow[b]{2}{*}{ Gender } & \multicolumn{2}{|c|}{ Study } & \multicolumn{2}{|c|}{ Controls } & \multirow{2}{*}{ P-value } \\
\hline & No & age $\%$ & No & age $\%$ & \\
\hline Male & 117 & 58.5 & 131 & 65.5 & \multirow{3}{*}{0.181} \\
\hline Female & 83 & 41.5 & 69 & 34.5 & \\
\hline Total & 200 & 100 & 200 & 100 & \\
\hline
\end{tabular}


Table 2: Comparison based on serum selenium and zinc levels between two groups as per gender.

\begin{tabular}{|c|c|c|c|c|c|}
\hline \multicolumn{6}{|c|}{ Selenium } \\
\hline \multirow[t]{2}{*}{ Gender } & \multicolumn{2}{|c|}{ Study Group } & \multicolumn{2}{|c|}{ Control Group } & \multirow[t]{2}{*}{ P-value } \\
\hline & Mean & SD & Mean & SD & \\
\hline Male & 54.1 & 11.12 & 108.0 & 27.60 & $<0.004^{*}$ \\
\hline Female & 54.4 & 10.30 & 99.1 & 25.09 & $<0.0012^{*}$ \\
\hline \multicolumn{6}{|c|}{ Zinc } \\
\hline & \multicolumn{2}{|c|}{ Study Group } & \multicolumn{2}{|c|}{ Control Group } & \multirow[t]{2}{*}{ P-value } \\
\hline Zinc & Mean & SD & Mean & SD & \\
\hline Male & 57.2 & 9.70 & 89.3 & 11.30 & $<0.0021^{*}$ \\
\hline Female & 56.2 & 6.03 & 85.6 & 13.90 & $<0.004^{*}$ \\
\hline
\end{tabular}

Table 3: Comparison based on serum selenium level and serum zinc level between two groups.

\begin{tabular}{|l|l|l|l|l|l|}
\hline & \multicolumn{2}{l}{ Study group } & \multicolumn{2}{l|}{ Control group } & \multicolumn{2}{l|}{ P value } \\
\hline & Mean & SD & Mean & SD & \\
\hline Se & 54.2 & 10.76 & 105.7 & 27.18 & P $<0.002$ \\
\hline Zn & 56.8 & 8.37 & 88.3 & 12.12 & P $<0.0011$ \\
\hline
\end{tabular}

Normal range of serum zinc level: $60-120 \mu \mathrm{g} / \mathrm{dl}$; Normal range of serum selenium level: $76-205 \mu \mathrm{g} / \mathrm{dl}$

$p<0.05)$ between them. The mean serum selenium level in men and women with oesophageal cancer patient was $54.1 \mu \mathrm{g} / \mathrm{dl}$ and $54.4 \mu \mathrm{g} / \mathrm{dl}$ respectively with no significant difference as shown in Table 2 . The mean serum zinc level in men and women with oesophageal cancer patient was $57.2 \mu \mathrm{g} / \mathrm{dl}$ and $56.2 \mu \mathrm{g} / \mathrm{dl}$ respectively with no significant difference as shown in Table 2.

\section{Discussion}

The findings of the present study indicate a strong association of Zinc, and Selenium with esophageal cancer. Both cases and controls were of same socio-economic status and dietary habits. In cancer esophagus there was significantly lower serum levels of Zinc and Selenium as compared to healthy controls.

A study conducted by MM Goyal, et al. [10], found significant low level of serum selenium and zinc while as high level of serum copper in carcinoma oesophagus patients, as compared to healthy controls. Similar results were found in our study that serum selenium levels were significantly decreased in study group as compared to control group o ( $p$-value < 0.001) (Table 3).

Mark SD, et al. [11] reported that the squamous cell carcinoma oesophagus patients had significantly low levels of serum zinc as compared to age matched healthy controls. In the current study, we also observed significantly low levels of zinc in carcinoma oesophagus patients as compared to age matched healthy controls. The results of this study regarding low levels of zinc in cancer patients were consistent with the findings of Cunzhi, et al. [12], Yaman, et al. [13] and Mazdak, et al. [14].

Zinc is mainly required for DNA synthesis, cell division and protein synthesis. Zn directly stimulates DNA synthesis by altering the binding of $\mathrm{F}$ and $\mathrm{F} 3$ histones to
DNA so as to affect RNA synthesis. It has been hypothesised that $\mathrm{Zn}$ could be operating at several different levels and influencing lymphocyte monoclonal proliferation [15]. Selenium is important in the active centre of the Se-dependent GSH-Px. This enzyme has four subunits and each contains one selenium atom. It was suggested that selenium protects cell by inhibiting free oxygen radical production. Moreover an important antioxidant Vit. $\mathrm{E}$ is transported by selenoproteins. There is evidence for a direct relationship between GSH-Px activity and carcinogenesis [16]. Gender had no significant relationship with mean zinc level and mean selenium level were consistent with findings of Reza Khalili, et al. [17].

\section{Conclusion}

On the basis of low levels of serum selenium and zinc in the cancer oesophagus patients as compared to healthy age matched controls. We strongly suspect that the deficiency of trace elements like selenium and zinc may be playing a role as a risk factor in the development of cancer oesophagus. However further studies on larger sample size is required to establish it.

\section{References}

1. Siegel R, Naishadham D, Jernal A (2012) Cancer statistics, 2012. CA Cancer J Clin 62: 10-29.

2. Stewart BW, Kleihuesp (2003) World cancer report. IARC.

3. Khan NA, Ashraf Teli M, Mohibul Haq M, Bhat GM, Mohd $M$, et al. (2011) A survey of risk factors in carcinoma esophagus in Kashmir valley. Journal of Cancer Research and Therpeutics 7: 15-18.

4. Linwei Li, Chunpeng Zhang, Xiaoyan Li, ShihHsin Lu, Yun Zhou (2011) Retraction: The candidate tumor suppressor gene ECRG4 in hibits cancer cells migration and invasion in esophageal carcinoma. J Exp Clin Cancer Res 23.

5. Sarah B Umar, David E Fleischer (2008) Esophageal can- 
cer: Epidemiology, pathogenesis and prevention. Nat Clin Pract Gastroenterol Hepatol 5: 517-526.

6. Navarro Silvera SA, Rohan TE (2007) Trace elements and cancer risk: A review of the epidemiologic evidence. Cancer Causes Control 18: 7-27.

7. Jackson MI, Combs GF Jr (2008) Selenium and anti-carcinogenesis: Underlying mechanisms. Curr Opin Clin Nutr Metab Care 11: 718-726.

8. Rayman MP (2005) Selenium in cancer prevention: A review of the evidence and mechanism of action. Proc Nutr Soc 64: 527-542.

9. Mellow MH, Layne EA, Lipman TO, Kaushik M, Hostetler C, et al. (1983) Plasma zinc and vitamin A in human squamous carcinoma of the esohagus. Cancer 51: 1615-1620.

10. MM Goyal, AK Kalwar, RK Vyas, A Bhati (2006) Study of serum zinc, selenium and copper levels in carcinoma of esophagus patients. Indian journal of clinical biochemistry 21: 208-210.

11. Mark SD, Qiao L, Dawsey SM, Wu YP, Katki H, et al. (2000) Prospective study of serum selenium levels, incident esophageal and gastric cancers. J Natl Cancer Institute 92: 1753-1763.
12. Cunzhi H, Jiexian J, Xianwen Z, Jingang G, Shumin Z, et al. (2003) Serum and tissue levels of six trace elements and copper/zinc ratio in patients with cervical cancer and uterine myoma. Biol Trace Elem Res 94: 113-122.

13. Yaman M, Kaya G, Simsek M (2007) Comparision of trace elements concentrations in cancerous and noncancerous human endometrial and ovary tissues. Int J Gynecol Cancer 17: 220-228.

14. Mazdak H, Yazdekhasti F, Movahedian A, Mirkheshti N, Shafieian M (2010) The comparative study of serum iron, copper, and zinc levels between bladder cancer patients and a control group. Int Urol Nephrol 42: 89-93.

15. Prasad AS (1991) Discovery of human Zn deficiency and studies in an experimental human model. Am J Clinic Nutr 53: 403-412.

16. Yalcin O, Karatas F, Erulas FA, Ozdemir E (2004) The level of glutathione peroxidase, vitamin $A, E, C$ and lipid peroxidation in patients with transitional cell carcinoma of the bladder. BJU Int 93: 863-866.

17. Reza Khalili Dizaji, Babak Rashidian, Mohammad Bahadoram, Maedeh Barahman, Bayazid Ghaderi, et al. (2018) Evaluation of serum zinc level as a risk factor for gastrointestinal cancers Immunopathol Persa. 4. 